\title{
A DISPUTA ENTRE O TERRITÓRIO TRADICIONAL QUILOMBOLA- PESQUEIRO DE RIO DOS MACACOS E O TERRITÓRIO MILITARIZADO DA MARINHA DO BRASIL
}

\author{
THE DISPUTE BETWEEN THE \\ TRADITIONAL QUILOMBOLA-FISHING \\ TERRITORY OF RIO DOS MACACOS \\ AND THE MILITARIZED TERRITORY \\ OF THE BRAZILIAN NAVY
}

Paula Regina de Oliveira Cordeiro paulareginacordeiro@gmail.com

Doutoranda do Programa de Pós-Graduação da Universidade Federal da Bahia (UFBA). Professora Substituta da Universidade do Estado da Bahia (UNEB). Pesquisadora do Grupo Costeiros (UFBA) e do Núcleo da Nova Cartografia Social (UFRB).

Orcid: https://orcid.org/0000-0002-5832-3860

\section{RESUMO}

A história vivenciada sobre o território tradicional quilombola-pesqueiro de Rio dos Macacos (Bahia) e a capacidade que essa comunidade tem em permanecer nesse território representam, sem dúvida, o mote principal desse trabalho. Presentes nas terras e águas do território desde pelo menos o século XIX, vivenciaram a escravização e o processo de libertação até a presente época. Processo no qual suas identidades quilombolas e pesqueiras foram ecoadas pelos quatro cantos do mundo, devido ao conflito com a Marinha do Brasil. A Marinha chega efetivamente ao território a partir da década de 1970 e começa a alterar as territorialidades tradicionais, expulsa moradores, estupra mulheres, proíbe as práticas produtivas, impede o acesso ao principal rio da comunidade e afirma serem as terras e as águas como pertencentes ao território da Vila Naval, militarizando o cotidiano. Paralelamente, os/as quilombolas-pescadores/as de Rio dos Macacos continuam a assumir o leme de suas vidas e se afirmam como os donos legítimos do território. Eis que se inicia uma disputa pelo território e também o início da disputa por modos de vida. Esse trabalho é uma tentativa de sistematizar as práticas espaciais dos/as quilombolas-pescadores/as de Rio dos Macacos, bem como da Marinha do Brasil. Investigar e recuperar os principais elementos e acontecimentos jurídicos-técnicos-políticos que envolvem o conflito. Ao passo que as práticas espaciais são narradas, as cartografias vão aparecendo, materializando dois territórios: o território quilombola-pesqueiro do Quilombo Rio dos Macacos, repleto de memórias, sonhos, sentimentos e sentidos; e o território militarizado, que tenta se impor ao longo do tempo. A solução do conflito territorial e a preservação do território tradicional têm relação direta com o acesso a políticas públicas e a regularização fundiária completa do território, significando que não apenas os espaços de moradia devem ser considerados, mas também os usos tradicionais, o que inclui o pleno acesso compartilhado dos cursos hídricos, incluso o Rio dos Macacos e das áreas de agricultura e extrativismo.

Palavras-chave: Território Quilombola-Pesqueiro. Quilombo Rio dos Macacos. Marinha do Brasil. 


\begin{abstract}
The lived history in traditional quilombola-fishing territory of Rio dos Macacos and the capacity that that community has to remain in the territory is, without a doubt, the main motto of this work. Present in the lands and waters of the territory since at least the nineteenth century, they experienced enslavement; the process of liberation continues into the present day as their identity as quilombolas and fishing communities were echoed in the four corners of the earth because of their conflict with the Brazilian Navy. The Navy arrived in the territory starting in the 1970s and began to alter the traditional territorialities, expelling residents, raping women, prohibiting productive practices, barring the community's main river, and asserting that the land and water belonged to the territory of the Naval Villa, militarizing everyday life. In parallel, the quilombolas/ fishing communities of Rio dos Macacos continue to assume control of their lives and affirm themselves as legitimate owners of the territory. Thus began a dispute over territory, but also a dispute over ways of life. This work is an attempt to systematize the spatial practices of the quilombolas/fishing communities of Rio dos Macacos, as well as the Brazilian Navy. I investigate and recover the principle juridical-technical-political elements and occurrences that encompass the conflict. As the spatial practices are narrated, the cartographies show the materialization of two territories: the quilombola-fishing territory of Quilombo Rio dos Macacos, replete with memories, dreams, feelings, and senses, and the militarized territory that attempts to impose itself over time. The solution to the territorial conflict and the preservation of the traditional territory has a direct relation with the access to public policy and the complete land regularization of the territory, meaning that not just the lived spaces should be considered, but also the traditional uses which include the shared use of water sources, including the Macacos River and the areas of agriculture and extraction.
\end{abstract}

Keywords: Traditional Quilombola-Fishing Territory. Quilombo Rio dos Macacos. Brazilian Navy.

\title{
DO RIO DOS MACACOS AO TERRITÓRIO QUILOMBOLA-PESQUEIRO DE RIO DOS MACACOS
}

O Quilombo Rio dos Macacos está localizado na Região Metropolitana de Salvador (RMS): seu território encontra-se nos limites dos municípios de Salvador e de Simões Filho, estando mais de 90\% em Simões Filho. É uma comunidade negra e rural, com influência da RMS e possui cerca de 80 famílias atualmente.

Ao Norte, faz fronteira com 150 famílias assentadas pelo sindicato dos trabalhadores rurais de Mapele (Simões Filho) na área pertencente atualmente à SUDIC (Superintendência de Desenvolvimento Industrial e Comercial da Bahia) e por comunidades do bairro de Aratu (Simões Filho); ao Sul, o quilombo é limitado pelos bairros de Valéria e Paripe (Salvador); a Leste, pela Via Periférica; a Oeste, pela BA-528 e pelo bairro de Paripe (Salvador); a Noroeste, estão o bairro de São Tomé (Salvador) e a Baía de Aratu (Figura 1).

A memória da comunidade afirma que seu território teve início com a compra do Engenho e da Usina Aratu, em 1783, pelo então capitão Manoel de Oliveira Barrozo. Segundo o Relatório Técnico de Identificação e Delimitação (RTID) do INCRA, em 1822 existiam 74 escravizados no Engenho açucareiro de Aratu. Em 1930, ocorre a desativação da Usina Aratu. Foi nessa usina que boa parte dos moradores de Rio dos Macacos trabalhou. Outras fazendas estão presentes na memória dos quilombolas-pescadores/as, são elas a Meireles e a Macacos, que faziam fronteiras com o engenho Aratu. 
Figura 1 - Localização do Quilombo Rio dos Macacos - RMS (BA)

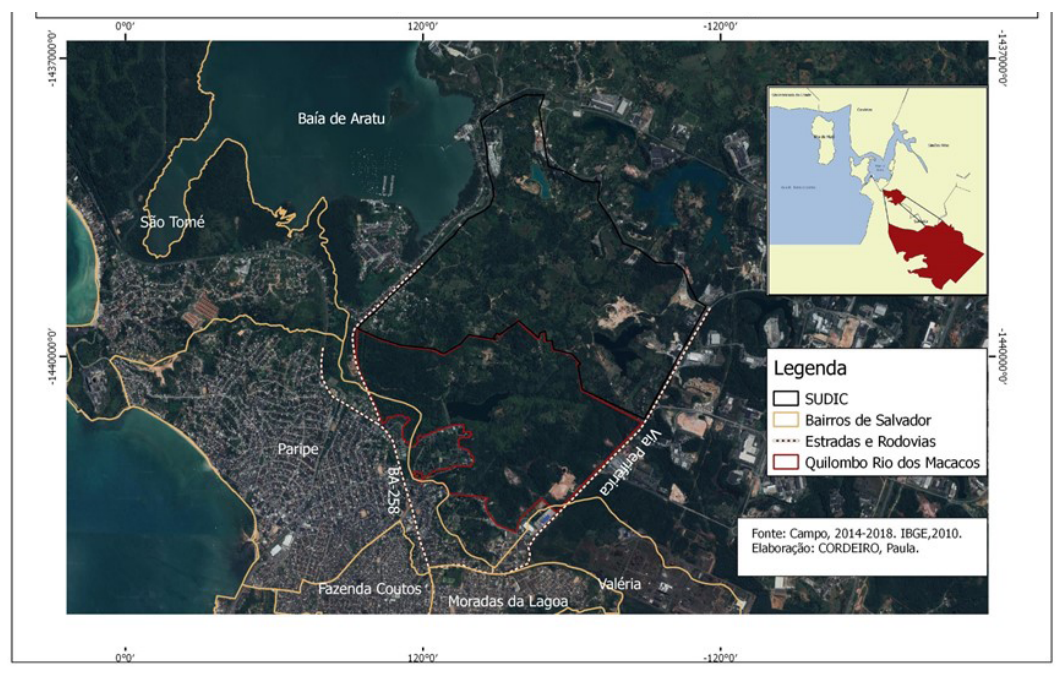

Fonte: Campo, 2014-2018. IBGE, 2010. Elaboração: CORDEIRO, Paula.

Com o passar do tempo, com a falência das fazendas e sem a presença dos fazendeiros, os antigos trabalhadores foram reconstruindo suas práticas espaciais a partir da criação de suas roças, do extrativismo, da pescaria e da mariscagem. Boa parte da produção era utilizada para a subsistência, bem como comercializada com a população ao redor e em feiras, como a do bairro de Paripe; a do Japão, no bairro da Liberdade e a de Água de Meninos, no bairro do Comércio em Salvador.

Com seus 91 anos de idade, dona Maria ${ }^{1}$ é uma fonte inestimável da vida da comunidade, já que nasceu e foi criada no território. Ela nasceu em uma casa que ficava entre o rio do Barroso e o rio da Prata. Dona Maria afirma que seu pai trabalhou como escravizado na fazenda Macacos, sob o controle de Coriolano. Dona Maria relembra que em tempos anteriores sua família trabalhava nas roças de café, mandioca e que faziam farinha. Sua mãe - e ela posteriormente - lavava roupas de ganho. Maria nunca saiu da comunidade, tendo morado em diversas localidades.

Dona Maria se emociona bastante ao falar de sua infância e adolescência, quando saía para mariscar e pescar na Baía de Aratu (principalmente ali, onde hoje é a Base Naval de Aratu); na Ilha de São João dos Martins, em Mapele; na barragem dos Oitis; nos rios dos Macacos e do Barroso, onde pegava grandes peixes de água doce. Relembra com muita emoção os sambas, os carurus, os batizados e a alegria que circundava a vida dos moradores.

Sua filha, Dona Olinda, fala ainda da grande presença de terreiros de candomblé no "nosso território quilombola-pesqueiro". Relembra com muita vitalidade as festas e as feituras de santo realizadas, as oferendas colocadas sob as gameleiras - que representam o próprio Orixá Irôko ${ }^{3}$, a quem é dedicado o culto ao Nkisi Tempo ${ }^{4}$. Conta também que os locais onde estão presentes as gameleiras e os cursos hídricos, com destaque às fontes de Luzia $^{5}$ e da Saúde, são extremamente importantes para a manutenção das tradições realizadas anteriormente pela sua vó, sua mãe e por ela.

O território ancestral ${ }^{6}$ do Quilombo Rio dos Macacos se constitui a partir das vivências nessas antigas fazendas (Figura 2). 
Figura 2 - Território Ancestral do Quilombo Rio dos Macacos

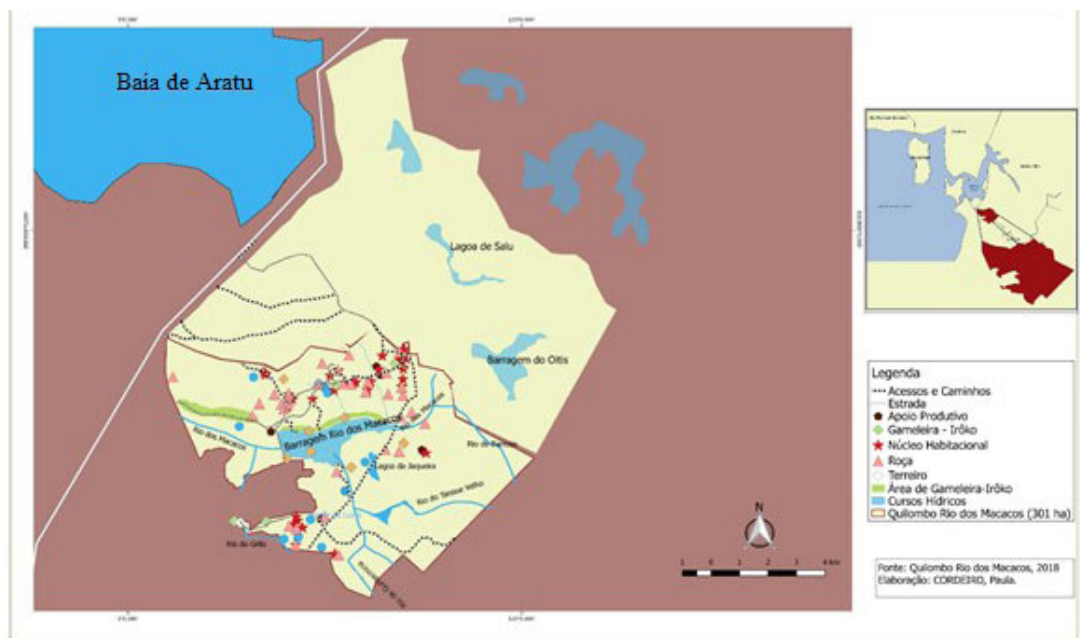

Fonte: Quilombo Rio dos Macacos, 2018. Elaboração: CORDEIRO, Paula.

Esse é o território dos sambas de roda que animam as festas, as rezas, o trabalho nas casas de farinha. Aos toques do violão, do cavaquinho, do pandeiro, do triângulo e do atabaque, somavam-se as sambadeiras. É o território também dos mestres Deraldo, Zé Deodato, Hugo e Renilson, que faziam suas rodas e treinos de capoeira na beira da praia e no mangue de Aratu.

\section{CONSTITUIÇÃO DE NOVA TERRITORIALIDADE: O REFAZER TRADICIONAL}

A territorialidade de Rio dos Macacos começa a ser modificada em meados da década de 1950, processo consolidado na década de 1970, com o barramento do Rio dos Macacos e a construção da Vila Naval da Barragem. A partir de então, as vidas serão refeitas e novas práticas espaciais realizadas.

As terras atualmente ocupadas pelos/as quilombolas-pescadores/as de Rio dos Macacos podem ser acessadas basicamente por duas entradas. A primeira e principal é pela portaria da Vila Naval da Barragem, outra entrada é pela Ilha de São João a norte do território. Ao acessar a entrada da Vila Naval da Barragem, após passarmos pelas ruas Bahia e Rio de Janeiro, e em meio às edificações da Marinha, encontra-se a entrada (Figura 3) para a casa de Dona Maria, a mesma Dona Maria que habitou essas terras anteriormente à presença da Marinha. 


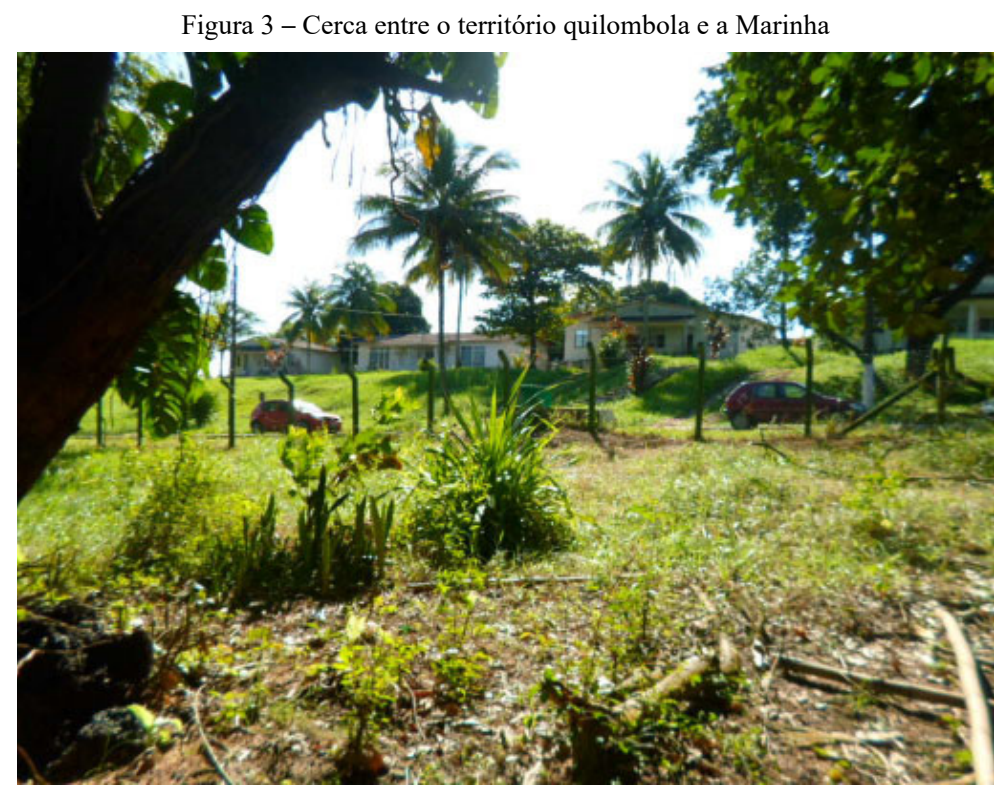

Fonte: CORDEIRO, 2015. Fotografia tirada no terreno de Dona Maria. A cerca foi colocada pela Marinha e separa os dois territórios. Do lado de cá da cerca, os/as quilombolas; do outro lado, a Marinha com seus carros e habitações.

Saindo da casa de Dona Maria, voltando pela rua Rio de Janeiro, até a rua Bahia, há a entrada da barragem do Rio dos Macacos, na qual existe uma estrada de barro que leva ao norte do território. O portão (Figura 4) que dá acesso à comunidade e ao oeste da barragem do Rio dos Macacos, assim como as cercas e demais portões existentes, marca a existência de outra territorialidade.

Figura 4 - Entrada para a Barragem do Rio dos Macacos

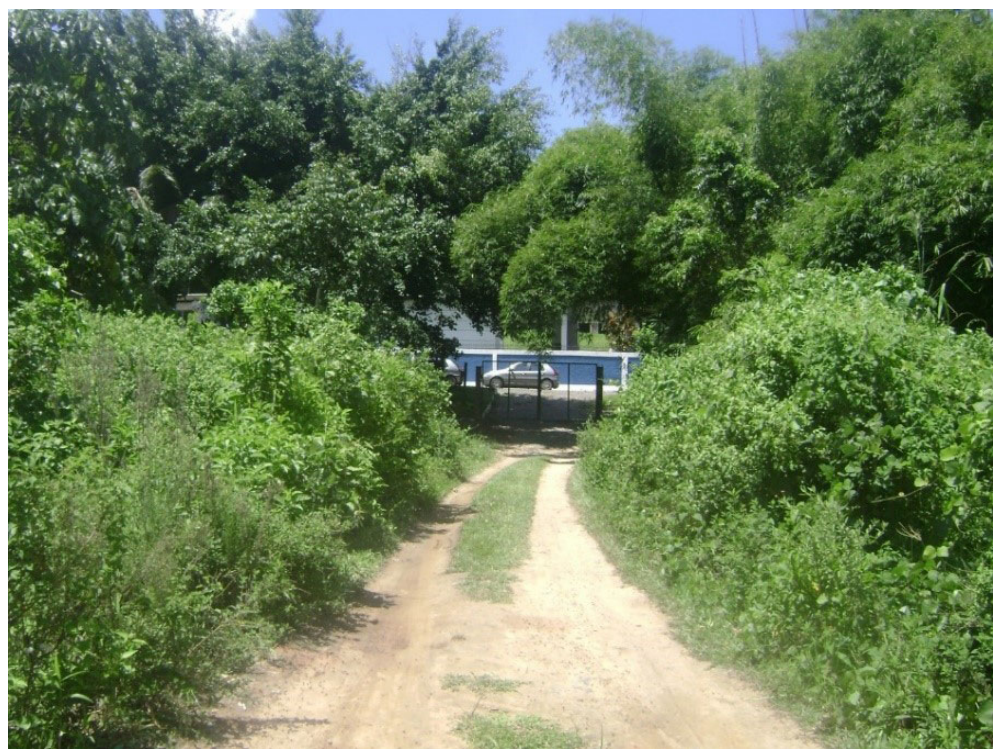

Fonte: CORDEIRO, 2018

A territorialidade "do lado de dentro do portão"7 é marcada pelo modo de vida tradicional. As casas são sempre acompanhadas por entornos ricos de vida. Somados à flora e fauna, encontram-se também os equipamentos e espaços de trabalho: são inúmeras as cozinhas e os espaços destinados à lavagem de roupas e de louças. São aqui também que os homens e mulheres preparam-se para a execução de atividades diversas. No entorno das moradias há plantação 
de hortaliças, tomateiros, alfaces, repolhos. Sem dúvida, o principal orgulho da comunidade é a sua produção.

A centralidade da produção na vida comunitária é notada pela diversidade de equipamentos e petrechos de pesca e de trabalho na roça no entorno das casas. Nelas, são cultivadas roças de feijão, milho, aipim, amendoim, pés de batata doce, batatinha do reino, buri, café, cana-de-açúcar, outras ervas, fruta-pão. Essas plantações somam-se às árvores frutíferas, compondo a paisagem. São diversas árvores presentes no território: mangueiras, pitangueiras, jaqueiras, abacateiros, abieiros, cajueiros, cajazeiras, jambeiros, cacaueiros, laranjeiras, mamoeiros, pés de mané-veio, bananeiras, entre outras.

O extrativismo também é muito importante aqui, principalmente os relacionados aos produtos do dendê $\hat{e}^{8}$. Ao realizar a retirada do dendê, este é beneficiado e transformado em azeite.

Aspecto importante da identidade é a atividade pesqueira, descrita como fundamental para a sobrevivência econômica da comunidade. No que diz respeito à pesca artesanal (Figura 5), a comunidade Rio dos Macacos possui como característica fundamental a pesca na barragem do Rio dos Macacos e na Baía de Aratu, desempenhando importante função na vida da comunidade.

Figura 5 - Pescaria no Rio dos Macacos

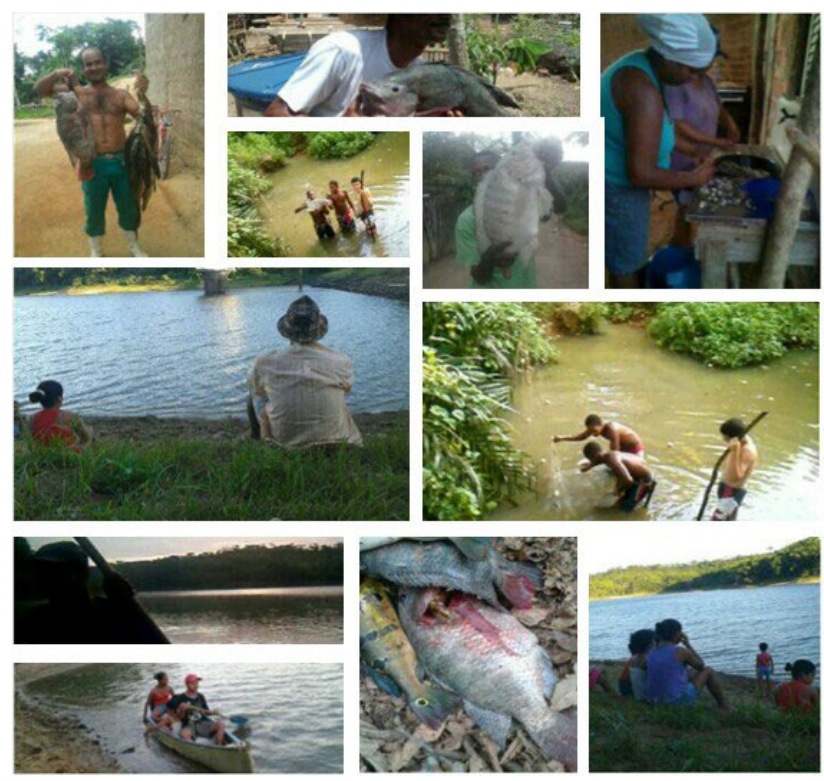

Fonte: Somos Quilombo Rio dos Macacos, 2016.

A pesca na barragem do Rio dos Macacos congrega tanto a pesca em si, como também se transforma em momento de lazer e nas brincadeiras e pescarias os adultos ensinam as crianças, e elas se divertem aprendendo. Raimundo ${ }^{9} \mathrm{diz}$ que quando é tempo de pescaria, eles/as vão de barco até determinado lugar da barragem, armam a rede de tardinha e deixam lá até o outro dia de manhã, quando vão pegar. Ele diz que o rio tem uma diversidade de pescados, mas eles preferem pegar a traíra, o tucunaré, a tilápia, o camarão e o peixe $\mathrm{CD}$, que, segundo Raimundo tem um primo na água salgada: o peixe galo. Após a pescaria, é hora do beneficiamento do pescado.

A atividade da pesca exige um calendário que leve em consideração as fases da lua. A melhor lua para a realização da atividade pesqueira é a lua cheia. Nesse momento, as marisqueiras se reúnem para mariscar, estabelecendo no território pesqueiro relações sociais e culturais que vão organizar a própria vida 
social comunitária. $\mathrm{O}$ circuito da atividade pesqueira envolve desde o conhecimento da natureza, as confecções dos instrumentos de trabalho, o conhecimento do território pesqueiro, o acesso ao território pesqueiro ${ }^{10}$, até o beneficiamento e comercialização do pescado.

\section{A MARINHA: O TERRITÓRIO MILITARIZADO}

Com o barramento do Rio dos Macacos e a construção da Vila Naval da Barragem, a Marinha se territorializa cada vez mais. Dona Maria conta que nos períodos iniciais ela foi parteira, lavadeira e cozinheira dos fuzileiros. Diz que o primeiro parto de uma criança, filha do militar Wilson, foi realizado por ela, anteriormente à construção da Vila Naval.

No início das obras da barragem, Dona Maria teve sua casa expropriada e a Marinha "deu" outro pedaço de terra para que ela fizesse sua casa. A instalação da Marinha no território fora marcada pela imposição de novos fluxos e estranhas dinâmicas. Dentre essas, destacam-se a expulsão de moradores, o estupro de mulheres, os espancamentos, o impedimento da construção ou reformas de suas casas, a negação da manutenção das culturas de subsistência através dos roçados, bem como a proibição de utilização dos rios, córregos, fontes, além do ataque direto à religiosidade quilombola, consolidado no fechamento e destruição de terreiros de candomblé. Com a construção da Vila da Marinha, as habitações dos moradores antigos deram lugar a prédios e grandes casas.

As proibições não param por aí, era proibido o acesso aos serviços básicos como energia elétrica, saneamento básico e abastecimento de água. Seu Edgar ${ }^{11}$ diz que por muito tempo teve que improvisar para ter energia elétrica. Essa era a norma no território, fato que só seria mudado com o início do fornecimento de energia elétrica pela Coelba, em 2016, único serviço existente até os dias atuais na comunidade.

\section{PERMANÊNCIA DAS “GRAFAGENS ESPACIAIS"}

Apesar de toda a violência e tentativas de expulsão, os/as quilombolas-pescadores/as de Rio dos Macacos enfrentam com resistência quase 5 décadas e permanecem no território. Apesar de muitos terem sido expulsos, boa parte permaneceu até os dias atuais. Mas em 2009, a Marinha do Brasil impetra uma ação reivindicatória requerendo a desocupação da área militar situada no entorno da Vila Naval. Foi a primeira de 4 ações ajuizadas com o mesmo objetivo.

Em novembro de 2010 foi proferida a primeira decisão interlocutória determinando a desocupação do local, não sem resistência. Foi quando o Quilombo Rio dos Macacos assume com firmeza sua identidade quilombola afirmando a preexistência de seus habitantes em relação à chegada da Marinha: "Nós somos os verdadeiros donos deste território. E se alguém tem que sair, são os navais", afirma Seu Edgar.

Devido à capacidade de organização e articulação, a comunidade consegue que a decisão seja suspensa e que comece o processo de afirmação de identidade e de disputa territorial, agora também no campo judicial. Com a ameaça de perder seu modo de vida, a comunidade inicia um processo de 
mobilização pela permanência no território, e em paralelo, entra com o pedido de titulação da área - como prevê o artigo 68 da Constituição Federal do Brasil de 1988, e como garante a Convenção 169 da Organização Internacional do Trabalho (OIT) - e aciona a identidade quilombola.

No mês de setembro de 2011, a Fundação Cultural Palmares (FCP) certifica o Quilombo Rio dos Macacos como uma Comunidade Remanescente de Quilombo (CRQ), e em novembro do mesmo ano, o Instituto Nacional de Colonização e Reforma Agrária (INCRA) inicia a elaboração do Relatório Técnico de Identificação e Delimitação (RTID). O RTID foi apresentado à comunidade em agosto de 2012 e delimitou o território quilombola em 301 hectares (ha). Apesar de elaborado, o RTID não foi publicado imediatamente pelo INCRA no Diário Oficial da União (DOU), impedindo a continuidade do processo de regularização fundiária.

\section{NEGOCIAÇÕES EM TORNO DO TERRITÓRIO}

Com os impedimentos colocados à publicação do RTID, tem-se início a mesa de negociação entre a Marinha do Brasil, a Secretaria Geral da Presidência da República, a Secretaria de Políticas para Promoção da Igualdade Racial (SEPPIR), o Quilombo Rio dos Macacos e suas assessorias, contando com a mediação do Ministério Público Federal e da subprocuradora-geral da República, Deborah Duprat, no momento coordenadora da $6^{\text {a }}$ Câmara de Coordenação e Revisão do Ministério Público Federal. É necessário lembrar que a Câmara de Conciliação instalada foi fruto da insistência política dos quilombolas, que não aceitavam de forma alguma sua expulsão ou a "transferência da comunidade" para uma "área crua", como afirma seu Joselito" ${ }^{12}$.

A primeira proposta feita pelo Estado à comunidade foi de 7,5 ha. Esses se encontravam fora do território quilombola. Em dezembro de 2012, a Secretaria Geral da Presidência da República apresenta a "Proposta do Governo Federal para a Comunidade do "Rio dos Macacos"”' e propõe 21 ha para titulação da comunidade. Em março de 2013 o Comando do $2^{\circ}$ Distrito Naval envia um ofício a Carlos Mário Guedes de Guedes, então presidente do INCRA, referente às informações solicitadas sobre a Vila Naval da Barragem. Segundo o Comando do $2^{\circ}$ Distrito Naval o:

[...] Relatório Técnico de Identificação de Delimitação (RTID), elaborado nos autos do referido Processo Administrativo, delimitou como território quilombola o Tombo da VNB, área pertencente à União, afetada à Marinha do Brasil (MB), de importante interesse estratégico para esta Força. Dessa forma, cumpre demonstrar que o Tombo da VNB configura uma área de segurança nacional, devendo, portanto, serem adotadas as medidas cabíveis para garantir a sustentabilidade da suposta 'comunidade quilombola', conciliando os interesses do Estado, conforme preconizado no art. 11, do Decreto $n^{\circ} 4.887 / 2003$ (MARINHA DO BRASIL, 2013, p. 1).

Apesar de expressar seu entendimento constitucional, a Marinha nesse documento, mas não só nele, questiona a identidade quilombola do grupo, o que fere o princípio da autoatribuição, além de expressar também o desejo de ver diminuída a comunidade e o próprio texto constitucional. No decorrer do documento, esse elemento aparece com mais força: 
O que se percebe é que a certificação dos réus como comunidade remanescente de quilombo teve o escopo de tentar reverter a situação processual, de modo a amenizar a representação judicial considerada deficiente, em razão da ausência de interposição de recurso da antecipação dos efeitos da tutela, o que tornou a decisão imutável (MARINHA DO BRASIL, 2013, p. 4).

Em sequência afirma que:

(...) o processo administrativo conduzido pela FCP contém, também, diversos vícios formais e materiais, que implicam na nulidade da certidão de autodefinição da 'Comunidade Rio dos Macaco' e, por conseguinte, no processo administrativo instaurado pelo INCRA, para a delimitação e titulação do respectivo território (MARINHA DO BRASIL, 2013, p. 4).

Em todo o ofício, a Marinha tenta impor a visão de que há, por parte dos quilombolas, a tentativa de enganar o Estado, e que as versões deles devem ser suprimidas. Segundo o ofício é dever do Estado "devolver" as terras da Marinha, "legítima dona". Segundo afirma o mesmo documento, a área é estratégica por ser de segurança nacional, por abrigar a barragem de Rio dos Macacos, construída para abastecer a Base Naval Militar, segundo a Marinha do Brasil:

A ocupação irregular se encontra distribuída desordenadamente pelo entono da Barragem dos Macacos, que é abastecida por nascentes as quais se encontram ameaçadas em face das ações destrutivas dos ocupantes irregulares, que promovem desmatamentos, queimadas, uso irregular de recursos hídricos, emissão de dejetos e lixos (MARINHA DO BRASIL, 2013, p. 4).

Como se percebe, a Marinha ataca a comunidade por dois caminhos: o primeiro é pela tentativa de descaracterizá-la enquanto comunidade quilombola, dizendo que os/as quilombolas estão se aproveitando da legislação vigente para fazer retroceder o processo judicial de desocupação em curso. Esse processo pode ser descrito como a tentativa de branqueamento do território (SANTOS, 2017). Mesmo que não sejam apenas pessoas brancas a morarem dentro da Vila Naval da Barragem, a estrutura colonial-branca está presente na formulação e ordenamento do território. Para Renato Emerson dos Santos (2017), o processo de branqueamento do território é entendido a partir de três dimensões: o branqueamento da ocupação, o branqueamento da imagem, o branqueamento da cultura. Gabriel Siqueira Corrêa (2017) complementa:

Essas dimensões sintetizam a tentativa de invisibilização e reconstrução sob a lógica eurocêntrica de 'territórios não brancos', ou seja, o apagamento da presença das grafagens espaciais (SANTOS, 2009), das geo-grafias (PORTO-GONÇALVES, 2003) negras e indígenas do território brasileiro (CORRÊA, 2017, p. 123).

Ainda segundo Corrêa (2017):

A tentativa de branqueamento que envolveu diretamente um conjunto de políticas no ordenamento territorial (nas mais diversas escalas), que possuiu como impacto o controle sobre a reprodução da vida de grupos populacionais. Nesse sentido, expulsão, marginalização, quando não o genocídio, marcaram um processo de exclusão da população negra do acesso ao território. Esta prática, não só não terminou com o tempo, mas sob novos discursos ganhou força no cenário atual (CORRÊA, 2017, p. 118-119).

O segundo caminho é o da criminalização desses a partir da legislação ambiental. Segundo a Marinha os quilombolas seriam responsáveis pela 
degradação ambiental e poluição das águas que abastecem a Barragem do Rio dos Macacos. Na verdade, as áreas de maior degradação ambiental do território são frutos, provavelmente, de usos indevidos da Marinha, incluindo aqui os dois únicos cursos hídricos que estão completamente poluídos e se encontram dentro da área da Vila Naval da Barragem, a saber: o trecho próximo à foz do Rio dos Macacos e o Rio do Grilo.

Em todo o documento a Marinha chama os quilombolas-pescadores/ as de Rio dos Macacos de "ocupantes irregulares" (MARINHA DO BRASIL, 2013), mesmo que seus documentos (registros, cartográficos) afirmem, como já fora dito, a presença anterior destes/as no território agora em conflito. Por fim, afirma constantemente a necessidade de ponderar a execução da legislação quilombola no caso em questão, já que "este Comando defende que devem prevalecer os interesses do Estado de manutenção da Área de Segurança, indispensáveis aos imperativos de Defesa Nacional, bem como de preservação de recursos hídricos da área invadida (sic)" (MARINHA DO BRASIL, 2013, p. 9).

Fato é que em outubro de 2013, as negociações continuam e o Governo Federal, através de uma nova audiência pública, fez a terceira proposta à comunidade, de 28,5 hectares. Essa proposta era a soma dos 7,5 ha e 21 ha oferecidos anteriormente, e assim como as demais propostas, essa também não foi aceita, já que para a Associação de Moradores "torna inviáveis a sobrevivência e reprodução física, econômica e cultural dos quilombolas" (ASSOCIAÇÃO QUILOMBOLA DE RIO DOS MACACOS, 2013).

Em 6 de maio de 2014, a Associação de Moradores do Quilombo Rio dos Macacos apresenta a primeira proposta (mapa 19, fotografia 66). A "contraproposta" apresentada pelos/as quilombolas-pescadores/as se insere no contexto de negação da proposta de 86 hectares apresentada anteriormente. O elemento principal de divergência com essa proposta é a negação dos cursos hídricos: o único curso hídrico que ficaria no interior da comunidade é intermitente e insuficiente para manutenção dos hábitos e modo de vida de uma comunidade pesqueira. Outro elemento negativo foi o impedimento do acesso à barragem para uso da comunidade, além da desarticulação com a parte sul do território.

A contraproposta apresentada pela Comunidade tinha como princípio o compartilhamento da barragem, a preservação dos sítios sagrados (Gameleiras e locais de arrego de oferenda) e a consolidação de área de produção agrícola e agroflorestal. A área negociada pela comunidade é a de 28 hectares para Marinha do Brasil, dos 301 hectares. Disto restariam para o uso, ocupação e desenvolvimento dos quilombolas 273 hectares. Em 6 de junho de 2014, após apresentação da contraproposta por Rose Meire ${ }^{13}$ e Dona Olinda, ao contrário do que se esperava, não houve questionamentos sobre a delimitação: a fala dos quilombolas gerou desconforto nos órgãos públicos seguido da indiferença destes. $\mathrm{Na}$ ocasião, "Seu Wiliam" lembrou que mesmo com o andar das negociações, eles (os/as quilombolas-pescadores/as) estavam sofrendo ameaça de remoção por conta do processo judicial de desapropriação ainda em curso. Nesse sentido, a subprocuradora-geral da República, Deborah Duprat, afirmou que a continuação desse processo inviabiliza as negociações, pois os/as quilombolas-pescadores/as se sentem pressionados/as para negociar. Após essa declaração, a comunidade pede a suspensão da audiência pública.

Após a suspensão da audiência, o governo federal apresentou ${ }^{14} \mathrm{o}$ que seria a quinta proposta à comunidade. $\mathrm{O}$ diferencial da proposta apresentada anteriormente é que além dos 86 ha ao norte da barragem, haveria a inclusão de 6 hectares ao sul da Vila Naval, com mais 12 ha do terreno da SUDIC (ao norte da barragem), totalizando uma área de 104 ha. A comunidade novamente rejeitou a proposta, já que essa mantém os aspectos básicos da anterior: a negação 
dos recursos hídricos e do uso compartilhado da barragem; assim como sugere uma divisão do território quilombola, propondo dois núcleos quilombolas.

Porém, após audiência pública, a nota oficial do Governo Federal, através do Ministro Gilberto Carvalho, afirma que: "não havendo o acordo, não há muito o que fazer, porque a Marinha não pode retirar a ação que move na Justiça, para reintegrar aquela área" (BRASIL, 2014). Ainda segundo o ministro, "o Governo Federal ainda está aberto a retomar as negociações, desde que os quilombolas revejam sua posição e aceitem a delimitação apresentada na reunião, uma vez que ela contempla os interesses dos diversos órgãos federais envolvidos na questão". (BRASIL, 2014). Em agosto de 2014 o INCRA publica o RTID porém, ao invés dos 301 ha identificados e delimitados, há a publicação de 104 ha.

Esse procedimento segundo o INCRA "reconhece uma área enquanto legítima dos quilombolas, porém a regularização só deverá acontecer onde os 'interesses do Estado' não são ameaçados”, conforme exigiu a Marinha em 2012. Seguindo os procedimentos para a regularização fundiária, em novembro de 2015 foi publicada a Portaria $\mathrm{n}^{\circ} 623$ de reconhecimento do território quilombola.

Essa não é uma situação vivenciada apenas pelos quilombolas de Rio dos Macacos. Há um vasto quadro atual da não-titulação dos territórios quilombolas. De 2005 até 2017 foram emitidas 2.455 certidões quilombolas: segundo os dados do INCRA, no mesmo período, foram elaborados 259 Relatórios Técnicos de Identificação e Delimitação (RTID), com a publicação de 82 decretos, 141 portarias e emissão de 116 títulos. Destes 99 são títulos parciais e apenas 17 quilombos tiveram a titulação completa de seus territórios (Quadro 1).

Quadro 1 - Dados da Regularização Quilombola no Brasil 2005-2017

\begin{tabular}{|c|c|c|c|c|c|}
\hline $\begin{array}{c}\text { Certidões } \\
\text { Quilom- } \\
\text { bolas }\end{array}$ & \multirow{2}{*}{$\begin{array}{c}\text { RTID } \\
\text { Elaborados }\end{array}$} & Decretos & Portarias & \multicolumn{2}{|c|}{ Títulos } \\
\cline { 5 - 6 } & & & Parciais & Integral \\
\hline $2.455(100 \%)$ & $259(10 \%)$ & $82(3 \%)$ & $141(6 \%)$ & $99(4 \%)$ & $17(0,7 \%)$ \\
\hline
\end{tabular}

Fonte: INCRA, 2018. Elaboração: CORDEIRO, 2018.

Na Bahia, no mesmo período, foram certificadas 596 comunidades quilombolas, destas, no período entre 2004 e 2017, 292 comunidades abriram processos no INCRA para a regularização fundiária. Segundo dados do INCRA, entre 2005 e 2017 apenas 36 comunidades possuem processos em andamento. Destas, 19 possuem RTID elaborados ou em fase de elaboração, 7 possuem decretos publicados, 4 possuem a portaria publicada, 3 possuem a Concessão do Direito Real de Uso, apenas 3 possuem a titulação parcial dos seus territórios e nenhuma possui a titulação integral de seu território (Quadro 2).

Quadro 2 - Dados da Regularização Fundiária na Bahia

\begin{tabular}{|c|c|c|c|c|c|c|c|c|}
\hline \multirow{2}{*}{ 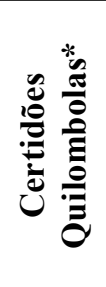 } & \multirow{2}{*}{ 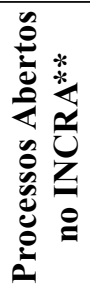 } & \multirow{2}{*}{ 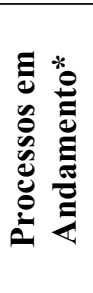 } & \multirow{2}{*}{ 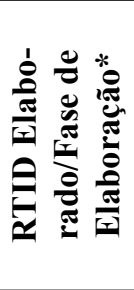 } & \multirow{2}{*}{ 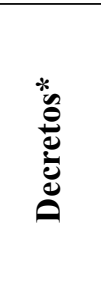 } & \multirow{2}{*}{ 苞 } & \multirow{2}{*}{ 菅 } & \multicolumn{2}{|c|}{ Títulos* } \\
\hline & & & & & & & لَّ & 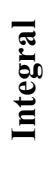 \\
\hline $\begin{array}{c}596 \\
(100 \%)\end{array}$ & 292 & $\begin{array}{c}36 \\
(6 \%)\end{array}$ & $19(3 \%)$ & $7(1 \%)$ & $\begin{array}{c}4 \\
(0,7 \%)\end{array}$ & $\begin{array}{c}3 \\
(0,5 \%)\end{array}$ & $\begin{array}{c}3 \\
(0,5 \%)\end{array}$ & 0 \\
\hline
\end{tabular}

Fonte: INCRA, 2018. * Dados de 2005 a 2017. ** Dados de 2004 a 2017. Elaboração: CORDEIRO, 2018. 
É perceptível a disparidade entre o reconhecimento da identidade quilombola e a garantia de seus direitos territoriais. Os dados apresentados acima são alarmantes, pois mostram a negligência com que estão sendo tratados os territórios quilombolas no Brasil. Se no Brasil existem apenas 116 titulações territoriais, esse número piora quando se percebe que, destes, apenas 17 possuem a titulação integral de seus territórios. Na Bahia, território com expressiva concentração quilombola, nenhum quilombo teve seus direitos territoriais respeitados. A titulação parcial dos territórios quilombolas se tornou uma norma nos processos de regularização fundiária, contrariando o decreto 4887/2003, deixando esses territórios vulneráveis e atuando no sentido de conferir legalidade às invasões externas aos territórios quilombolas. Nesse sentido, apesar das legislações criadas na estrutural de Estado, este se coloca também como aliado do processo de destruição do modo de vida quilombola. No caso do Quilombo Rio dos Macacos, o Estado (a Marinha) é o próprio antagonista.

\section{(IN) CERTEZAS E FRAGMENTAÇÃO DO TERRITÓRIO À GUISA DE CONCLUSÃO}

Se a delimitação anterior de 301 ha resguardava os/as quilombolas-pescadores/as e reconhecia como território quilombola as áreas de terra e água, a delimitação de 104 ha desconsidera por completo a característica pesqueira dessa comunidade. O mapa abaixo (Figura 6) serve de base para a compreensão de qual território foi destinado à regularização pelo Governo Federal, bem como demonstra a insuficiência dessa destinação para a manutenção do modo de vida.

Figura 6 - Mapa de Perda de Território Pesqueiro-Quilombola (Quilombo dos Macacos - Bahia)

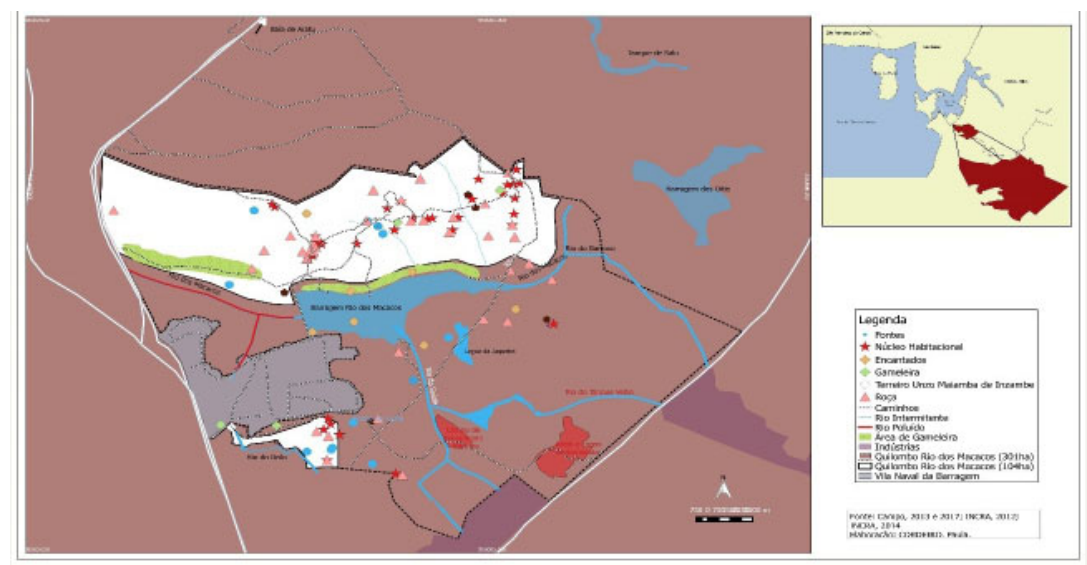

Fonte: Campo, 2013 e 2017; INCRA, 2012; INCRA, 2014. Elaboração: CORDEIRO, Paulo.

O mapa acima demonstra que o projeto de 104 ha intensifica a fragmentação do território. Desde a chegada da Marinha o território quilombola-pesqueiro de Rio dos Macacos foi comprometido, mas com a possibilidade de regularizar apenas os 104 ha, o território será dividido em duas glebas sem continuidade e articulação territorial: a primeira, localizada na área norte-noroeste do território, possui 98,2755 ha; a segunda possui 5,8057 ha e está localizada a sudoeste. A princípio essa proposta ignora e desrespeita a decisão quilombola contrária a fragmentação territorial. Não se trata apenas da questão quantitativa do território, mas também das questões culturais e identitárias: a existência de um território continuo no Quilombo - "Um Quilombo só" -, é condição necessária para a sua reprodução. 
A fragmentação desencadeará um processo de fratura ou quebra, o território que era um se transformará em dois fragmentos, são duas partes quebradas, isoladas, desunidas, desconectadas. Uma parte não se mantém sem a outra, sem as outras. Aqui, a fragmentação terá relação direta com a destruição da unidade. Os 104 ha foram nitidamente demarcados considerando apenas as moradias. O modo de vida e as formas de trabalho foram desconsiderados. Mesmo se pensarmos nas moradias, alguns núcleos habitacionais ficaram de fora do limite de 104 ha.

São quase 90 famílias vivendo no território: como será possível abarcar essa quantidade de famílias nesse número reduzido de hectares? Dos 104 hectares ficam de fora as áreas de extrativismo e todos os cursos hídricos permanentes, além das fontes sagradas.

No mês de fevereiro de 2018 foi realizada nova audiência pública, seis anos após a elaboração do RTID. A Audiência Pública teve como principais pontos abordados (I) a titulação definitiva do território quilombola, (II) o acesso e uso compartilhado da água da barragem do Rio dos Macacos, (III) o acesso e a garantia de políticas públicas, dentre elas a construção de estradas e caminhos independentes à portaria da Vila Naval da Marinha.

A audiência contou com a presença do vice-procurador-geral da República, Luciano Mariz Maia (atual coordenador da $6^{\mathrm{a}}$ câmara do MPF), contou ainda com a presença também de representantes do Conselho Nacional de Direitos Humanos, da Defensoria Pública da Bahia, da Associação dos/as Advogados/as de Trabalhadores Rurais (AATR) e de Universidades.

Sem dúvida, o ponto mais controverso foi o uso compartilhado da Barragem do Rio dos Macacos entre os/as quilombolas-pescadores/as e a Marinha. Nas palavras do Comandante:

\begin{abstract}
Eu tenho a autorização pelo meu Almirante de efetuar uma proposta de utilização, de certo modo compartilhado, colocando um portão efetivamente próximo da barragem, depois do muro já construído e com a segurança necessária para todo o pessoal das 514 residências existentes dentro da Vila Naval da Barragem (...) Eu li que a demanda da Comunidade Rio dos Macacos pela barragem é acesso à água para a pesca e acesso à água para os ritos de matrizes afrodescendentes. Aquelas pessoas que tiverem efetivamente um cadastro de alguma entidade de pesca e apresentarem essa documentação poderão ter acesso, desde que efetivamente sejam encaminhadas, do mesmo modo para os ritos de matrizes africanas (MPF, 2018).
\end{abstract}

Essa proposta apresenta pelo menos três problemas principais: o primeiro deles é a imposição de uma restrição, o portão representa outras restrições impostas pela Marinha outrora, o que impossibilita a utilização independente e autônoma dos/as quilombolas-pescadores/as ao Rio, necessário para a manutenção do modo de vida tradicional. O segundo problema é que boa parte dos/ as pescadores/as não possui o RGP, pois a política da pesca, enfrenta sérios problemas e há mais de 2 anos os/as pescadores/as deram entrada na solicitação e não tiveram retorno. $\mathrm{O}$ terceiro problema é que não existe uma carteira ou formas de comprovar a religiosidade. Esse é um direito constitucional e todas as pessoas têm o direito de exercer de forma livre.

Após a fala do Comandante, Rose Meire, liderança da Comunidade, faz uma fala avaliando a proposta colocada pela Marinha:

Boa tarde a todos e a todas, primeiramente os mais velhos. Assim, escutar uma fala que já aconteceu quando eu tinha a idade de 7 anos 
se repetir nessa mesa com meus 39 anos... É difícil, doutor Luciano, escutar essas coisas, porque eu sou uma das pessoas que sabe a dor da perda em questão de violência, em questão do Governo Federal, da Marinha de guerra do Brasil. E infelizmente tem alguns militares que usam essa farda para destruir a nação, porque eu sou a nação. Então assim, é difícil ouvir essa fala em questão de portão que já aconteceu de ter um portão em cima da barragem, retirando a inda e a vinda da comunidade, retirando todos os direitos que a comunidade tem, com dois homens com fuzis na mão, espancando criança, idoso, adolescente e todas as gerações. Eu sou uma dessas crianças que foi espancada ali. (...) A gente sabe, a Marinha de Guerra do Brasil sabe o que acontece lá dentro do quilombo em questão das violências. Então assim, a gente não pode permitir esse portão, para que mulheres sejam estupradas como já aconteceu ali em cima e vários tipos de violência aconteceu ali porque a gente ia pegar água. A gente não pode aceitar em questão daquele muro que vai destruir a nossa comunidade, as nossas vidas. A gente não quer o domínio da barragem, a gente quer o uso compartilhado da água (SANTOS - AUDIÊNCIA MPF, 2018).

Em tom de exaustão ela afirma "A gente não quer o domínio da barragem, a gente quer o uso compartilhado da água". O fato é que se o território tradicional não for preservado, essa comunidade perderá suas características rurais e suas fronteiras serão invadidas pela expansão do urbano e, como consequência, haverá a favelização desta.

Após outra audiência, o futuro do Quilombo Rio dos Macacos é incerto. A Marinha já começou a construir o muro em torno da barragem, enfrentando resistência direta dos/as quilombolas-pescadores/as. A tentativa de descaracterização do território tradicional iniciado em 1970 foi coroado na medida em que o Estado destina 104 hectares para a regularização fundiária, desconsiderando a múltipla identidade dos agentes sociais: pesqueira e quilombola. $\mathrm{O}$ território virou um joguete nas negociações dentro do Estado, a vida dos/as quilombolas-pescadores/as de Rio dos Macacos sofre cada vez mais com a ausência de políticas públicas, as privações de acesso ao seu território, indispensável ao modo de vida tradicional. Até o momento, o processo de regularização fundiária ainda não foi concluído e as proibições da Marinha do Brasil (do Estado) se mantêm ${ }^{15}$.

\section{NOTAS}

${ }^{1}$ Respeitando a decisão das/os quilombolas, seus nomes completos serão ocultados nesse trabalho.

${ }^{2}$ Entrevista realizada em junho de 2015, no Quilombo Rio dos Macacos.

${ }^{3}$ Divindade-Orixá cultuado no Brasil sobretudo pela nação Ketu.

${ }^{4}$ Divindade-Nkisi cultuado no Brasil sobretudo pela nação Angola.

${ }^{5}$ Luiza, que mesmo após seu falecimento, continua uma referência na comunidade quilombola.

${ }^{6}$ A adjetivação "ancestral" foi utilizada pelos próprios sujeitos, quando eles estão se referindo ao território anteriormente ocupado por seus anteriores, seus ancestrais.

${ }^{7}$ Expressão de Seu Edgar, liderança quilombola falecida.

${ }^{8}$ Fruto da Palmeira Dendezeiro (Elaeis guineensis).

${ }^{9}$ Quilombola e liderança.

${ }^{10} \mathrm{O}$ acesso ao território pesqueiro é regulado, muitas vezes, pelas intervenções externas. Muitas vezes os pescadores conhecem o território, porém não possuem pleno acesso.

${ }^{11}$ Seu Edgar faleceu após seu neto Evanildo ter sido espancado na portaria da Vila Naval. 
${ }^{12}$ Liderança quilombola que, após ser expulsa pela Marinha, mora fora do território.

${ }^{13}$ Rose Meire é uma das principais lideranças da luta do Quilombo Rio dos Macacos. Ela não pode sair sozinha, pois já foi ameaçada de morte diversas vezes. É protegida em programa de Defensores de Direitos Humanos.

${ }^{14}$ A proposta não foi apresentada oficialmente, pois Deborah Duprat suspendeu a Audiência Pública devido à ameaça de desapropriação sofrida pela comunidade.

${ }^{15}$ São inúmeros os crimes executados pela Marinha do Brasil que não foram julgados. Se na década de 90 e início de 2000 imperava os estupros, os espancamentos. Em 2014 duas lideranças da comunidade foram agredidas, fortemente espancadas e torturadas no momento em que saiam do território pela principal via existente: a portaria da Vila Naval. Notícia da Folha de Saõ Paulo "Em vídeo, militares agridem líder quilombola que pediu ajuda a Dilma" <http://www1.folha.uol.com.br/poder/2014/02/1411074-em-video-militares-agridem-lider-quilombola-que-pediu-ajuda-a-dilma.shtml $>$. Em 2015, Evanildo de 17 anos foi espancado pelos fuzileiros navais. Em 2017, estudantes e professores da Universidade Federal do Recôncavo foram barrados. Em 2018, a Marinha fechou o acesso à água e colocou fuzileiros impedindo o acesso à barragem, pois os pescadores colocaram uma rede de pesca no dia anterior.

\section{REFERÊNCIAS}

ASSOCIAÇÃO QUILOMBOLA DE RIO DOS MACACOS. Sobre proposta de regularização fundiária do Governo Federal. 2013

BRASIL. Quilombolas do Rio dos Macacos rejeitam acordo proposto pelo Governo Federal que atende grande parte de suas reivindicações. Disponível em: http://www.secretariageral.gov.br/noticias/2014/05/09-05-2014-quilombolas-do-rio-dos-macacos-rejeitam-acordo-proposto-pelo-governo-federal-1. Acesso em: 09 mai. 2014.

CORDEIRO, Paula Regina de O. A militarização do cotidiano e a luta territorial na comunidade quilombola Rio dos Macacos: O território militarizado e o território da vida. Monografia (Graduação em Geografia) - Departamento de Geografia, Instituto de Geociências, Universidade Federal da Bahia, Bahia, Salvador, 2014.

CORDEIRO, Paula Regina de O.Essa terraéprafilh@s e net@s não vende e não pode trocar: A disputa entre o território tradicional quilombola-pesqueiro de Rio dos Macacos e o território militarizado da Marinha do Brasil. Dissertação (Mestrado em Geografia) - Programa de Pós-Graduação em Geografia, Instituto de Geociências, Universidade Federal da Bahia, Bahia, Salvador, 2018.

CORRÊA, Gabriel Siqueira. O branqueamento do território como dispositivo colonialidade do poder: notas sobre o contexto brasileiro. In: CRUZ, Valter do Carmo. Geografia e Giro Descolonial: Experiências, ideais e horizontes de renovação do pensamento crítico. Rio de Janeiro: Letra Capital, 2017.

INCRA. INSTITUTO NACIONAL DE COLONIZAÇÃO E REFORMA AGRÁFIA. Relatório Técnico de Identificação e Delimitação do Território da Comunidade Quilombola de Rio dos Macacos. Salvador, 2012.

MARINHA DO BRASIL. Processo fundiário do tombo da Vila Naval. 2013.

SANTOS, Renato Emerson. O movimento negro brasileiro e sua luta antirracismo: por uma perspectiva descolonial. In: CRUZ, Valter do Carmo. Geografia e Giro Descolonial: Experiências, ideais e horizontes de renovação do pensamento crítico. Rio de Janeiro: Letra Capital, 2017. 